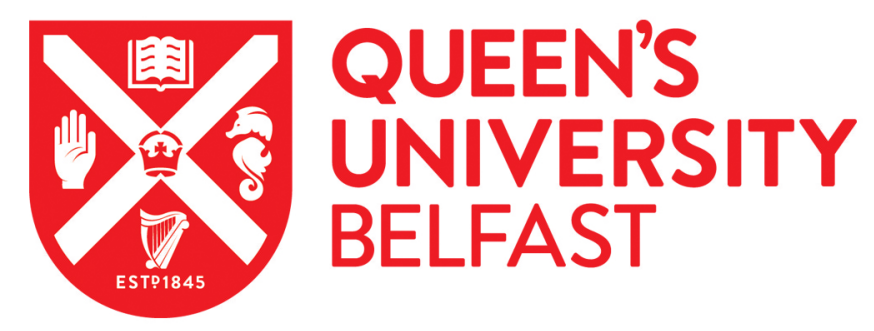

\title{
The influence of microplastics on trophic interaction strengths and oviposition preferences of dipterans
}

Cuthbert, R. N., Al-Jaibachi, R., Dalu, T., Dick, J. T. A., \& Callaghan, A. (2019). The influence of microplastics on trophic interaction strengths and oviposition preferences of dipterans. Science of the Total Environment, 651(2), 2420-2423. https://doi.org/10.1016/j.scitotenv.2018.10.108

Published in:

Science of the Total Environment

Document Version:

Peer reviewed version

Queen's University Belfast - Research Portal:

Link to publication record in Queen's University Belfast Research Portal

Publisher rights

Copyright 2018 Elsevier

This manuscript is distributed under a Creative Commons Attribution-NonCommercial-NoDerivs License

(https://creativecommons.org/licenses/by-nc-nd/4.0/), which permits distribution and reproduction for non-commercial purposes, provided the author and source are cited.

\section{General rights}

Copyright for the publications made accessible via the Queen's University Belfast Research Portal is retained by the author(s) and / or other copyright owners and it is a condition of accessing these publications that users recognise and abide by the legal requirements associated with these rights.

Take down policy

The Research Portal is Queen's institutional repository that provides access to Queen's research output. Every effort has been made to ensure that content in the Research Portal does not infringe any person's rights, or applicable UK laws. If you discover content in the Research Portal that you believe breaches copyright or violates any law, please contact openaccess@qub.ac.uk. 
Short Communication

The influence of microplastics on trophic interaction strengths and oviposition preferences of dipterans

Ross N. Cuthbert ${ }^{1,2^{*}}$, Rana Al-Jaibachi ${ }^{2}$, Tatenda Dalu ${ }^{3,4}$, Jaimie T.A. Dick ${ }^{1}$, Amanda Callaghan $^{2}$

${ }^{1}$ Institute for Global Food Security, School of Biological Sciences, Queen’s University Belfast, Medical Biology Centre, Belfast BT9 7BL, Northern Ireland

${ }^{2}$ Ecology and Evolutionary Biology, School of Biological Sciences, University of Reading, Reading RG6 6AS, England

${ }^{3}$ Department of Ecology and Resource Management, University of Venda, Thohoyandou 0950, South Africa

${ }^{4}$ South African Institute for Aquatic Biodiversity (SAIAB), Grahamstown 6140, South Africa

*Corresponding author: email, rcuthbert03@qub.ac.uk 


\begin{abstract}
Microplastic (MP) pollution continues to proliferate in freshwater, marine and terrestrial environments, but with their biotic implications remaining poorly understood. Biotic interactions such as predation can profoundly influence ecosystem structuring, stability and functioning. However, we currently lack quantitative understandings of how trophic interaction strengths and associated behaviours are influenced by MP pollution, and how transference of MPs between trophic levels relates to consumptive traits. We also lack understanding of key life-history effects of MPs, for example, reproductive strategies such as oviposition. The present study examines the predatory ability of non-biting midge larvae,
\end{abstract} Chaoborus flavicans, towards larvae of Culex pipiens mosquitoes when the latter are exposed to MPs, using a functional response (FR) approach. Transfer of MPs occurred from larval mosquitoes to larval midges via predation. Microplastics transfer was significantly positively related to predation rates. Predation by C. flavicans followed a Type II FR, with average maximum feeding rates of 6.2 mosquito larvae per hour. These and other FR parameters (attack rates and handling times) were not significantly influenced by the presence of MPs. Further, C. pipiens adults did not avoid ovipositing in habitats with high concentrations of MPs. We thus demonstrate that MPs can move readily through freshwater food webs via biotic processes such as predation, and that uptake correlates strongly with consumption rates. Further, as MPs do not deter adult mosquitoes from ovipositing, our experiments reveal high potential for MP exposure and transference through ecosystems.

\title{
Key words
}

food chain; predator-prey; microplastics transference; functional response; Chaoborus; Culex 


\section{Introduction}

Microplastic (MP; $<5 \mathrm{~mm}$ in size) pollution is prolific in terrestrial and aquatic ecosystems globally (Mason et al., 2018; Sighicelli et al., 2018; Wagner and Lambert, 2018). Whilst the enormous scale of MP pollution is unequivocal, we currently have a poor understanding of how MP presence influences interaction strengths between trophic groups (Wagner and Lambert, 2018). Interaction strengths between predators and prey can profoundly impact the infrastructure of ecosystems through the determination of predator population growth and prey population stability (Paine, 1980; Gilbert et al., 2014). Thus, understanding factors that influence predation are crucial to predicting ecosystem structure and functioning. Trophic transfer via predation has been identified as a potentially major pathway through which MPs can move through food webs (Batel et al., 2016; Chae et al., 2018; Nelms et al., 2018;

Provencher et al., 2018), however quantifications of how exposure to MP pollution influences trophic interaction strengths are lacking, especially in highly vulnerable, understudied freshwater environments (Blettler et al., 2018).

Functional responses (FRs) (Solomon, 1949; Holling, 1959) quantify resource use under different resource densities and are powerful predictors of interaction strengths between consumers and resources. Three FR types have been broadly characterised: Type I FRs are filter-feeder specific (Jeschke et al., 2004), wherein consumption increases linearly with resource densities; Type II FRs exhibit a decelerating intake rate, with high proportional consumption at low resource densities potentially leading to resource extirpation; Type III FRs are sigmoidal, characterised by low proportional consumption at low densities, thus potentially facilitating refugia for prey (Holling, 1949). For predators and prey, FRs can quantify how prey populations are regulated by predators across different contextdependencies (e.g. Cuthbert et al., 2018). Shifts in the FR form and/or magnitude of predators, for instance from destabilising Type II to stabilising Type III, are known to be 
driven by environmental contexts (Alexander et al., 2012). However, we currently have little quantitative bases to predict how pollutants such as MPs will influence predator-prey dynamics. Furthermore, distributions of prey populations are often reliant on selective processes relating to quantifications of risk and reward between habitat patches, especially for reproductive decisions such as oviposition sites (Nonacs and Dill, 1990). Indeed, the ability to avoid potentially harmful habitats can benefit the fitness of progeny and influence the success of populations. However, there has been little research to quantify the influence of MPs on selective behaviours, such as oviposition, which can drive species distributions and influence biotic interactions (Goldstein et al., 2012; Majer et al., 2012).

In the present study, we thus examine whether MP exposure modulates interaction strengths between predators and prey, and whether trophic MP transfer can be related to predation rates. We then discern MP implications for ovipositional behaviour. Focal organisms were larvae of the predatory non-biting midge Chaoborus flavicans, and filter-feeding larvae of the mosquito complex Culex pipiens, which often co-occur in natural and artificial aquatic habitats.

\section{Materials and methods}

\section{Experimental design}

Fluorescent $2 \mu \mathrm{m}$ yellow-green carboxylate-modified polystyrene MPs (density $1.050 \mathrm{~g} \mathrm{~cm}^{-3}$, 88 excitation $470 \mathrm{~nm}$; emission $505 \mathrm{~nm}$, Sigma-Aldrich, UK) were used in all experiments. Microplastics were stored as a stock suspension $\left(2.5 \mathrm{mg} \mathrm{mL}^{-1}\right)$ and mixed as per Al-Jaibachi et al. (2018a). Chaoborus flavicans $(1.0-1.2 \mathrm{~cm})$ larvae were purchased commercially (Northampton Reptile Centre, UK) and acclimated for 6 days in a laboratory at the University of Reading $\left(19 \pm 1^{\circ} \mathrm{C}, 16: 8\right.$ light:dark) on a diet of C. pipiens larvae in $5 \mathrm{~L}$ dechlorinated tapwater. Wild C. pipiens were collected from the Whiteknights campus of the University of 
Reading $\left(51^{\circ} 26^{\prime} 12.2^{\prime \prime} \mathrm{N}, 0^{\circ} 56^{\prime} 31.2^{\prime \prime} \mathrm{W}\right)$. Egg rafts of $C$. pipiens were sampled from artificial container habitats and, upon hatching, fed ad libitum on crushed rabbit food pellets in the same laboratory in $10 \mathrm{~L}$ dechlorinated tap-water. Gravid adult C. pipiens were collected overnight using modified gravid box traps with a hay and yeast infusion used as bait (see Townroe and Callaghan, 2014).

In experiment 1 , in the laboratory $\left(19 \pm 1^{\circ} \mathrm{C}, 16: 8\right.$ light:dark), groups of 400 C. pipiens larvae $(0.15-0.20 \mathrm{~cm})$ were exposed to one of two MP treatments $\left(0\right.$ particles $\mathrm{mL}^{-1}, 100$ particles $\mathrm{mL}^{-1}$ ) in $500 \mathrm{~mL}$ arenas for $22 \mathrm{~h}$, whilst predators were simultaneously starved. Following treatments, C. pipiens larvae were rinsed in dechlorinated tap water and introduced at 5 densities $(2,5,10,20,40 ; n=5$ per treatment group) into $20 \mathrm{~mL}$ arenas containing 10 $\mathrm{mL}$ dechlorinated tap-water. After $2 \mathrm{~h}$ of prey acclimation, predatory C. flavicans were introduced and allowed to feed for $2 \mathrm{~h}$. Predators were then removed and remaining live prey counted. Controls consisted of a replicate at each MP treatment and prey density in the absence of predators. Individual predators and prey were frozen at $-20{ }^{\circ} \mathrm{C}$ before homogenisation and filtration using nucleopore track-etched membranes (Whatman, UK) of $<$ $0.1 \mu \mathrm{m}$, with the MPs on filter membranes subsequently counted using an epi-fluorescent microscope (Zeiss Axioskop, Germany).

In experiment 2, thirty wild gravid adult C. pipiens were transferred into each of six $30 \mathrm{~cm}^{3}$ cages in a laboratory $\left(25 \pm 1^{\circ} \mathrm{C}, 16: 8\right.$ light:dark). Mosquitoes were allowed to oviposit in one of two paired $200 \mathrm{~mL}$ arenas containing different MP treatments $\left(0\right.$ particles $\mathrm{mL}^{-1}, 100$ particles $\mathrm{mL}^{-1}$ ), placed randomly in opposite corners of the cages, over 3 days. Egg rafts were enumerated and removed daily.

\section{Data analysis}


In experiment 1, the relationship between MP uptake via predation in C. flavicans and number of prey killed was examined using a generalised linear model (GLM) assuming Poisson error distribution. A GLM with quasi-Poisson error distribution was used to examine overall prey killed with respect to the 'MP treatment' and 'prey supply' factors, owing to residual overdispersion. Functional responses (FRs) were modelled using 'frair' in $R$ (Pritchard et al., 2017) with Rogers' random predator equation (Rogers, 1972). Attack rate and handling time parameters were non-parametrically bootstrapped to generate $95 \%$ confidence intervals and compared according to MP treatment using the delta method (Juliano, 2001). Handling time estimates were used to generate maximum feeding rates over the total feeding period $(1 / h)$.

In experiment 2 , total egg raft counts were analysed using a generalised linear mixed model with negative binomial distribution between paired MP treatments, owing to residual overdispersion. Cage number was included as a random slope and intercept to account for the paired experimental design.

\section{Results}

In experiment $1, C$. pipiens larvae exposed to 100 particles $\mathrm{mL}^{-1}$ contained $5.8 \pm 2.7$ (mean \pm SD) MPs, whilst prey not exposed to MPs did not contain MPs. Whilst MPs were not detected in predators following consumption of unexposed prey, transference occurred in all C. flavicans that killed MP-exposed C. pipiens. Microplastic transference from C. pipiens to C. flavicans via predation was significantly positively related to the number of prey killed ( $t$ $=1.972, p=0.049)$.

Survival of prey was $100 \%$ in predator-free controls, and so all prey deaths were assumed to be due to predation. Predation by C. flavicans did not differ significantly according to prey MP exposure $(t=0.959, p=0.343)$. Prey killed increased significantly with greater prey 
supplies $(t=4.938, p<0.001)$ and under both MP treatments given no significant interaction $(t=0.721, p=0.472)$. Chaoborus flavicans exhibited Type II FRs irrespective of prey MP exposure, given that first order terms were significantly negative in both treatment groups (Table 1). Attack rates (initial curve slopes) did not differ significantly between MP exposure treatments $(z=1.694, p=0.090)$, but trended towards being higher where larval C. pipiens were exposed to MPs prior. Handling times did not differ significantly between MP treatments $(z=1.087, p=0.277)$, although, reciprocally, maximum feeding rates (curve asymptotes) tended to be higher towards prey not exposed to MPs (Table 1). Confidence intervals for attack rates and handling times overlapped overall (Table 1), and across all prey densities between MP treatments (Figure 1), further indicating a lack of significant difference in FRs.

In experiment 2, a total of 43 egg rafts were oviposited in MP-treated water and 38 egg rafts in controls. There was no significant difference in oviposition between these treatment groups $(z=0.380, p=0.704)$ (Figure 2$).$ High statistical power, and thus low probability for Type II error, was found for both predation (power $=0.94)$ and oviposition $($ power $=0.93)$.

\section{Discussion}

Microplastics continue to proliferate across the biosphere, with ecological implications frequently unknown (Carlos de Sá et al., 2018; Mason et al., 2018; Sighicelli et al., 2018; Wagner and Lambert, 2018). In the present study, we further demonstrate active uptake of MPs through filtering by larval mosquitoes (Al-Jaibachi et al., 2018a, 2018b). Furthermore, we demonstrate that MPs can be transferred and retained trophically from filter feeding organisms to higher predators, and that trophic transference relates to consumption rates. Predation by larval C. flavicans towards larval mosquito prey was significant irrespective of prior prey exposure to MPs. Neither search efficiency (attack rate) or time taken to subdue, 
capture and digest prey (handling time) were significantly affected by prey MP exposure. Whilst both the area of attack rate and handling time parameters have been shown to be heavily context-dependent (e.g. Barrios-O’Neill et al., 2016; Cuthbert et al., 2018), here we show that the presence of MP pollution does not elicit changes to predation rates. Therefore, MPs are likely to be readily transferred to predators from prey in MP-polluted systems.

Larval Culex mosquitoes actively filter and retain MP particles, and MPs have been shown to transfer ontogenically from larval to pupal stages, and then to the terrestrial adult mosquito stage (Al-Jaibachi et al., 2018a, 2018b). As with mosquitoes, C. flavicans exhibits both aquatic and terrestrial life stages, and thus the potential for ontogenic transference of MPs via this species from aquatic to terrestrial environments is high, and could accordingly impact terrestrial vertebrates. Strong potential for MPs to move further through food chains and impact organisms has been demonstrated in other freshwater systems (Chae et al., 2018). In the present study, as transference across trophic stages was positively related to predation rates, uptake of MPs via predation may be related to intraspecific or intraindividual variations in consumptive traits. Indeed, such variabilities are often naturally present within populations, and could influence MP pollution impact (Alexander et al., 2015).

Oviposition by mosquitoes is selective across gradients of risk and reward (Pintar et al., 2018). The present study demonstrates that gravid adult Culex mosquitos are not deterred from ovipositing in aquatic habitats with MPs. Therefore, there is a high potential for larval stages to be exposed to MPs throughout their aquatic life stages, before subsequently transferring MPs trophically or ontogenically (Al-Jaibachi et al., 2018b). Although concentrations of MPs in the present study were high (but see Fischer et al., 2016; Su et al., 2016), the lack of effect of MPs on predation rates and oviposition suggests that similar observations could occur in environments with lower MP concentrations. 
It is probable that colonists are naïve to potential risks of MPs to fitness. However, AlJaibachi et al. (2018a) found that MPs have little influence on the survival and fitness of Culex mosquitoes across their life history. Whilst this is the first study to quantitatively link MP transfer with predation rates, work is required to further explore potential trophic accumulation of MPs, alongside behavioural implications, and to discern the potential for aerial dispersal of MPs by freshwater insects aside from mosquitoes (Al-Jaibachi et al., 2018b). Previous work has demonstrated the direct exploitation of MPs particles as oviposition sites by insects aside from mosquitoes in aquatic systems (Goldstein et al., 2012; Majer et al., 2012), and MPs are ingested by a range of other aquatic invertebrates (Nel et al., 2018; Windsor et al., 2019). Here, as larval chaoborids ingest prey whole before regurgitating undigested, solid material, examinations of physiological restrictions on MP retention are required for this group (Moore 1988), particularly given their ecological importance in freshwater environments (Riessen et al. 1984). Elucidations of environmental contextdependencies which modulate MP uptake and transfer rates would additionally be of value, alongside the time-dependent effects of depuration.

\section{References}

Alexander, M.E., Dick, J.T.A., O’Connor, N.E., Haddaway, N.R., Farnsworth, K.D., 2012. Functional responses of the intertidal amphipod Echinogammarus marinus: effects of prey supply, model selection and habitat complexity. Mar. Ecol. Prog. Ser. 468, 191202. (doi:10.3354/meps09978)

Alexander, M.E., Dick, J.T.A., O’Connor, N.E., 2015. Predation in the marine intertidal amphipod Echinogammarus marinus Leach: Implications of inter- and intraindividual variation. J. Exp. Mar. Biol. Ecol. 462, 50-54. (doi:j.jembe.2014.10.011) 
Al-Jaibachi, R., Cuthbert, R.N., Callaghan, A., 2018a. Examining effects of ontogenic microplastic transference on Culex mosquito mortality and adult weight. Sci. Tot. Environ. 651, 871-876. (doi:10.1016/j.scitotenv.2018.09.236)

Al-Jaibachi, R., Cuthbert, R.N., Callaghan, A., 2018b. Up and away: ontogenic transference as a pathway for aerial dispersal of microplastics. Biol. Lett. 14, 20180479. (doi:10.1098/rsbl.2018.0479)

Barrios-O'Neill, D., Kelly, R., Dick, J.T.A., Ricciardi, A., MacIsaac, H.J., Emmerson, M.C., 2016. On the context-dependent scaling of consumer feeding rates. Ecol. Lett. 19, 668-678. (doi:10.1111/2041-210X.12784)

Batel, A., Linti, F., Scherer, M., Erdinger, L., Braunbeck, T., 2016. Transfer of benzo[a]pyrene from microplastics to Artemia nauplii and further to zebrafish via a trophic food web experiment: CYP1A induction and visual tracking of persistent organic pollutants. Environ. Toxicol. Chem. 35, 1656-1666. (doi:10.1002/etc.3361)

Blettler, M.C.M., Abrial, E., Khan, F.R., Sivri, N., Espinola, S.A., 2018. Freshwater plastic pollution: Recognizing research biases and identifying knowledge gaps. Water Res. 143, 416-424. (doi:10.1016/j.watres.2018.06.015)

Carlos de Sá, L., Oliveira, M., Ribeiro, F., Rocha, T.L., Futter, M.N., 2018. Studies of the effects of microplastics on aquatic organisms: What do we know and where should we focus our efforts in the future? Sci. Total Environ. 645, 1029-1039. (doi:10.1016/j.scitotenv.2018.07.207)

Chae, Y., Kim, D., Kim, S.W., An, Y-J., 2018. Trophic transfer and individual impact of nano-sized polystyrene in a four-species freshwater food chain. Sci Rep. 8, 284. (doi:10.1038/s41598-017-18849-y) 
Cuthbert, R.N., Dick, J.T.A., Callaghan, A., Dickey, J.W.E., 2018. Biological control agent selection under environmental change using functional responses, abundances and fecundities; the Relative Control Potential (RCP) metric. Biol. Control 121, 50-57. (doi:j.biocontrol.2018.02.008)

Fischer, E.K., Paglialonga, L., Czech, E., Tamminga, M., 2016. Microplastic pollution in lakes and lake shoreline sediments - a case study on Lake Bolsena and Lake Chiusi (central Italy). Environ. Pollut. 213, 648-657. (doi:10.1016/j.envpol.2016.03.012)

Gilbert, B., Tunney, T.D., McCann, K.S., DeLong, J.P., Vasseur, D.A., Savage, V., Shurin, J.B., Dell, A.I., Barton, B.T., Harley, C.D.G., Kharouba, H.M., Kratina, P., Blanchard, J.L., Clements, C., Winder, M., Greig, H.S., O’Connor, M.I., 2014. A bioenergetic framework for the temperature dependence of trophic interactions. Ecol. Lett. 17, 902-914. (doi:10.1111/ele.12307)

Goldstein, M.C., Rosenberg, M., Cheng, L., 2012. Increased oceanic microplastic debris enhances oviposition in an endemic pelagic insect. Biol. Lett. 8, 817-820. (doi:10.1098/rsbl.2012.0298)

Holling, C.S., 1959. Some characteristics of simple types of predation and parasitism. Can. Entomol. 91, 385-398. (doi:10.4039/Ent91385-7)

Jeschke, J.M., Kopp, M., Tollrian, R., 2004. Consumer-food systems: why type I functional responses are exclusive to filter feeders. Biol. Rev. Camb. Philos. Soc. 79, 337-349. (doi:10.1017/S1464793103006286)

Juliano, S.A., 2001. Nonlinear curve fitting: predation and functional response curves, in: Scheiner, S.M., Gurevitch, J. (Eds.), Design and analysis of ecological experiments. Oxford University Press, UK, pp. 178-196. 
Majer, A.P., Vedolin, M.C., Turra, A., 2012. Plastic pellets as oviposition site and means of dispersal for the ocean-skater insect Halobates. Mar. Pollut. Bull. 64, 1143-1147. (doi:10.1016/j.marpolbul.2012.03.029)

Mason, S.A., Welch, V., Neratko, J., 2018. Synthetic polymer contamination in bottled water. Fredonia State Univ. New York, pp. 1-17.

Moore, M.V., 1988. Density-dependent predation of early instar Chaoborus feeding on multispecies prey assemblage. Limnol. Oceanogr. 33, 256-268. (doi:10.4319/1o.1988.33.2.0256)

Nel, H.A., Dalu, T., Wasserman, R.J., 2018. Sinks and sources: Assessing microplastic abundance in river sediment and deposit feeders in an Austral temperate urban river system. Sci. Total Environ. 612, 950-956. (doi:10.1016/j.scitotenv.2017.08.298)

Nelms, S.E., Galloway, T.S., Godley, B.J., Jarvis, D.S., Lindesque, P.K., 2018. Investigating microplastic trophic transfer in marine top predators. Envirol. Pollut. 238, 999-1007. (doi:10.1016/j.envpol.2018.02.016)

Nonacs, P., Dill, L.M., 1990. Mortality risk vs. food quality trade-offs in a common currency: ant patch preferences. Ecology 71, 1886-1892. (doi:10.2307/1937596)

Paine, R.T., 1980 Food webs: linkage, interaction strength and community infrastructure. $J$. Anim. Ecol. 49, 666-685. (doi:10.2307/4220)

Pintar, M.R., Bohenek, J.R., Eveland, L.L., Resetarits Jr, W.J., 2018. Colonization across gradients of risk and reward: Nutrients and predators generate species-specific responses among aquatic insects. Funct. Ecol. 35, 1589-1598. (doi:10.1111/13652435.13086) 
Pritchard, D.W., Paterson, R.A., Bovy, H.C., Barrios-O’Neill, D., 2017. frair: an R package for fitting and comparing consumer functional responses. Methods Ecol. Evol. 8, 1528-1534. (doi:10.1111/2041-210X.12784)

Provencher, J.F., Vermaire, J.C., Avery-Gomm, A., Braune, B.M., Mallory, M.L., 2018. Garbage in guano? Microplastic debris found in faecal precursors of seabirds known to ingest plastics. Sci. Total Environ. 644, 1477-1484.

(doi:10.1016/j.scitotenv.2018.07.101)

Riessen, H.P., O’Brien, W.J., Loveless, B., 1984. An analysis of the components of Chaoborus predation on zooplankton and the calculation of relative prey vulnerabilities. Ecology 65, 514-522. (doi:10.2307/1941413)

Rogers, D., 1972. Random search and insect population models. J. Anim. Ecol. 41, 369-383.

Solomon, M.E., 1949. The natural control of animal populations. J. Anim. Ecol. 18, 1-35

Su, L., Xue, Y., Li, L., Yang, D., Kolandhasamy, P., Li, D., Shi, H., 2016. Microplastics in Taihu Lake, China. Environ. Pollut. 216, 711-719. (doi:10.1016/j.envpol.2016.06.036)

Townroe, S., Callaghan, A., 2015. Morphological and fecundity traits of Culex mosquitoes caught in gravid traps in urban and rural Berkshire, UK. Bull. Entomol. Res. 105, 615-620. (doi:10.1017/S000748531500053X)

Wagner, M., Lambert, S., 2018 Freshwater Microplastics. Springer International Publishing, Switzerland. (doi:10.1007/978-3-319-61615-5)

Windsor, F.M., Tilley, R.M., Tyler, C.R., Ormerod, S.J., 2019. Microplastic ingestion by riverine macroinvertebrates. Sci. Total Environ. 646, 68-74. (doi:10.1016/j.scitotenv.2018.07.271) 
Sighicelli, M., Pietrelli, L., Lecce, F., Iannilli, V., Falconieri, M., Coscia, L., Di Vito, S., Nuglio, S., Zampetti, G., 2018. Microplastic pollution in the surface waters of Italian Subalpine Lakes. Environ. Pollut. 236, 645-651. (doi:10.1016/j.envpol.2018.02.008)

\section{Tables}

Table 1. First order terms from the proportion of prey killed as a function of prey density according to MP exposure treatments. Attack rate, handling time and maximum feeding rate parameters from Rogers' random predator equation and bootstrapped $(n=2000) 95 \%$ confidence intervals (CIs).

\section{Figure legends}

Fig. 1. Functional responses of larval Chaoborus flavicans towards larval Culex pipiens following exposure to different microplastic (MP) treatments (absent, 0 particles $\mathrm{mL}^{-1}$; present, 100 particles $\left.\mathrm{mL}^{-1}\right)$. Shaded area represents bootstrapped $(n=2000)$ confidence intervals.

Fig. 2. Number of egg rafts oviposited by Culex pipiens between paired treatments with microplastics (MPs) absent $\left(0\right.$ particles $\left.\mathrm{mL}^{-1}\right)$ or present $\left(100\right.$ particles $\left.\mathrm{mL}^{-1}\right)$.

\section{Ethics}

Ethics committee approval was not required.

\section{Data accessibility}

Data files are available in online supplementary material.

\section{Author contribution}


All authors provided substantial contributions to conception and design, or acquisition of data, or analysis and interpretation of data; were involved in drafting the article or revising it critically for important intellectual content; approved the final version to be published; and agree to be accountable for all aspects of the work in ensuring that questions related to the accuracy or integrity of any part of the work are appropriately investigated and resolved.

\section{Competing interests}

We declare we have no competing interests.

\section{Funding}

R.N.C. is funded through the Department for the Economy, Northern Ireland. 